\title{
Block one, unleash a hundred. Mechanisms of DAB2IP inactivation in cancer
}

\author{
Arianna Bellazzo ${ }^{1,2}$, Giulio Di Minin ${ }^{3}$ and Licio Collavin ${ }^{\star, 1,2}$
}

One of the most defining features of cancer is aberrant cell communication; therefore, a molecular understanding of the intricate network established among tumor cells and their microenvironment could significantly improve comprehension and clinical management of cancer. The tumor suppressor DAB2IP (Disabled homolog 2 interacting protein), also known as AIP1 (ASK1 interacting protein), has an important role in this context, as it modulates signal transduction by multiple inflammatory cytokines and growth factors. DAB2IP is a Ras-GAP, and negatively controls Ras-dependent mitogenic signals. In addition, acting as a signaling adaptor, DAB2IP modulates other key oncogenic pathways, including TNF $\alpha / N F-\kappa B$, WNT/ $\beta$-catenin, PI3K/AKT, and androgen receptors. Therefore, DAB2IP inactivation can provide a selective advantage to tumors initiated by a variety of driver mutations. In line with this role, DAB2IP expression is frequently impaired by methylation in cancer. Interestingly, recent studies reveal that tumor cells can employ other sophisticated mechanisms to disable DAB2IP at the post-transcriptional level. We review the mechanisms and consequences of DAB2IP inactivation in cancer, with the purpose to support and improve research aimed to counteract such mechanisms. We suggest that DAB2IP reactivation in cancer cells could be a strategy to coordinately dampen multiple oncogenic pathways, potentially limiting progression of a wide spectrum of tumors.

Cell Death and Differentiation (2017) 24, 15-25; doi:10.1038/cdd.2016.134; published online 18 November 2016

\section{Facts}

- The cytoplasmic Ras-GAP protein DAB2IP (Disabled-2 Interacting Protein) is a negative modulator of multiple oncogenic pathways.

- DAB2IP is rarely mutated, but frequently downregulated or inactivated in cancer by different mechanisms.

- Functional inhibition of DAB2IP in transformed cells favors a pro-oncogenic response to multiple extracellular inputs.

\section{Open questions}

- Are there other mechanisms or conditions for DAB2IP inactivation that may be relevant in cancer?

- Is it possible that DAB2IP modulates additional signaling pathways that have not been tested yet?

- We have limited knowledge about expression and activity of different DAB2IP isoforms. How are they regulated? Do they have specific functions?

- Given its impact on multiple oncogenic pathways, could reactivation or increased expression of DAB2IP protein be developed as a potential approach for cancer therapy?

The complexity of multicellular organisms depends on an intricate exchange of information that dynamically defines cell metabolism, shape, movement, proliferation, differentiation, and death. The transduction of signals into an appropriate biological response is thus critical for life. Whereas the nucleus is the end point where most information is converted into a biological response, cytoplasm is the place where different signals are integrated, attenuated, or amplified, and pathways can talk to each other as in a cellular 'agorà'.

DAB2IP is a tumor-suppressor protein capable of modulating the cytoplasmic steps of various oncogenic pathways. DAB2IP was initially discovered as a member of the RASGTPase (Ras-GAP) family, interacting with tumor suppressor DOC2/DAB2 (differentially expressed in ovarian carcinoma-2/ Disabled-2). ${ }^{1} \mathrm{~A}$ broader role of DAB2IP emerged when it was cloned as an interactor of ASK1 (apoptosis signal-regulating kinase 1) kinase; hence the alternative name AIP1 (ASKinteracting protein 1$){ }^{2}$ In the following years several studies explored the role of DAB2IP in various additional pathways, revealing its peculiar function as a middleman in signal transduction, dampening various major oncogenic pathways.

\section{DAB2IP: A Complex Gene Encoding a Negative Modulator of Multiple Oncogenic Pathways}

The human DAB2IP gene spans $\sim 218 \mathrm{~kb}$ on chromosome 9q33.1-q33.3. Multiple transcripts suggest the existence of at least four transcription start sites (TSS), encoding three possible $\mathrm{N}$-terminal variants of the protein. Alternative splicing of the last exon generates two different C-terminal variants, so that six DAB2IP protein isoforms can be

\footnotetext{
${ }^{1}$ Laboratorio Nazionale CIB, AREA Science Park, Trieste 34149, Italy; ${ }^{2}$ Dipartimento Scienze della Vita, Università degli Studi di Trieste, Trieste 34127 , Italy and ${ }^{3}$ Institute of Molecular Health Sciences, Swiss Federal Institute of Technology, ETH Hönggerberg, Zurich 8093, Switzerland

*Corresponding author: L Collavin, Laboratorio Nazionale CIB, University of Trieste, AREA Science Park, Padriciano 99, Trieste 34149, Italy. Tel: +39 40 3756802; Fax: +39 40 398990; E-mail: collavin@ Incib.it

Received 11.7.16; revised 26.9.16; accepted 12.10.16; Edited by G Melino; published online 18.11.16
} 

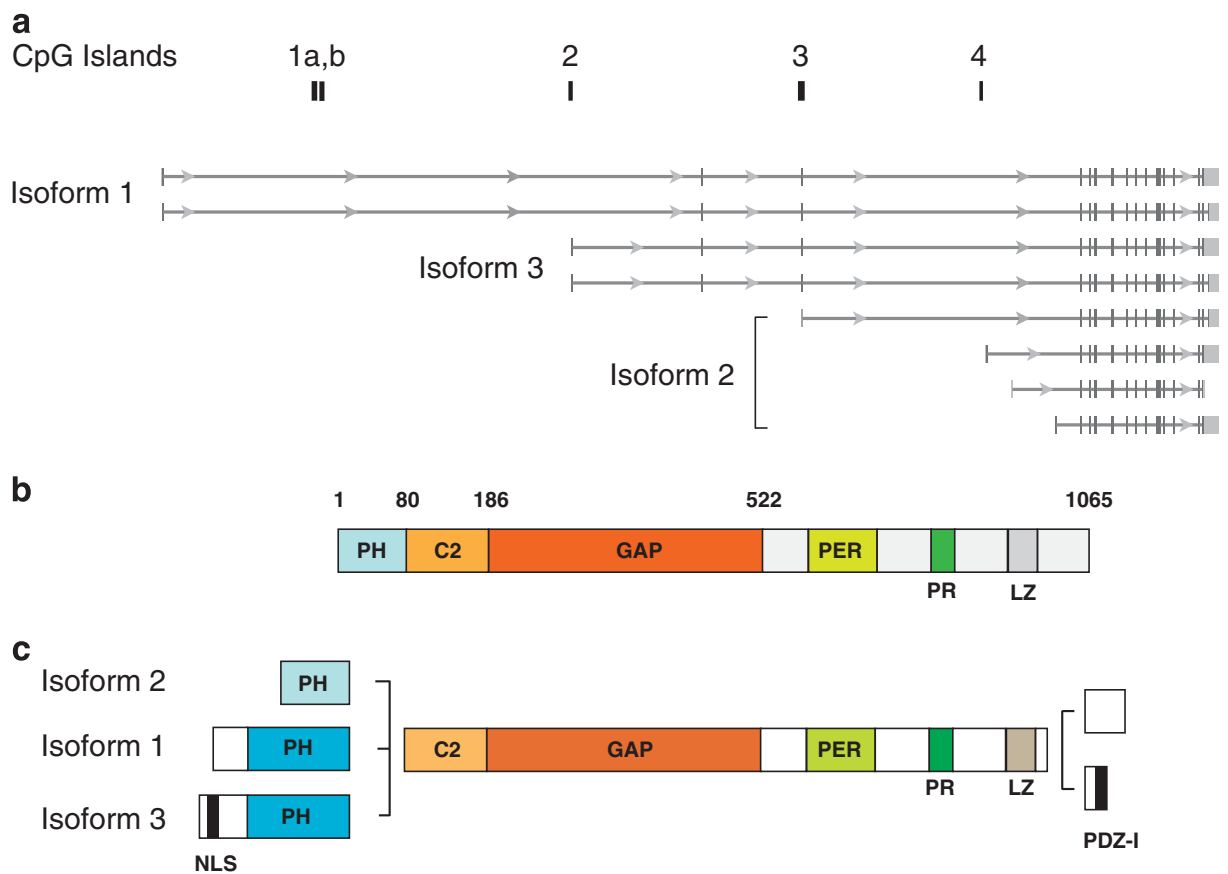

Figure 1 Structure of the human DAB2IP gene and encoded protein(s). DAB2IP modulates the response of cells to a variety of extracellular signals. Its functions depend on its modular structure highly conserved among mammals. Two human DAB2IP transcripts are currently annotated in RefSeq: variant 1 (NM_032552.3) and variant 2 (NM_138709.1). However, multiple additional DAB2IP transcripts have been detected, indicating the existence of at least four different TSSs, encoding three possible N-terminal variants of the protein. In addition, alternative splicing generates two possible C-terminal sequences so that a panel of DAB2IP isoforms can be potentially expressed. (a) Schematic of the main hDAB2IP transcripts and the relative position of $\mathrm{CpG}$ islands on the genome. The predicted protein isoforms encoded by the various transcripts are also indicated (data from NCBI, Homo sapiens Annotation Release 150). (b) Structure of hDAB2IP isoform 2, with main functional domains according to Zhang et al. ${ }^{2}$ (c) Structure of six predicted hDAB2IP isoforms, with possible combinations of alternative $\mathrm{N}$ - and $\mathrm{C}$ termini. Pleckstrin Homology (PH) domain: a protein module of $\sim 100$ amino acids that characterizes a wide range of proteins involved in intracellular signaling. It can bind phosphatidylinositol lipids within biological membranes, such as phosphatidylinositol $(3,4,5)$-triphosphate and phosphatidylinositol $(4,5)$-bisphosphate..$^{79}$ It can also mediate protein-protein interactions. DAB2IP isoforms 1 and 3 have a larger PH domain. C2 (Protein kinase $\mathrm{C}$ conserved region 2): a Ca2+ binding motif, 130 residues in length, found in many signaling proteins. This domain mediates binding to phospholipids, inositol phosphates, and other proteins. ${ }^{80}$ GTPase-Activating Protein domain (GAP): a catalytic domain that binds activated G proteins and promotes their GTPase activity. It can also mediate protein-protein interactions. ${ }^{81}$ Proline-rich domain (PR): a region mediating protein-protein interactions, in particular as a docking site for SH3 domains. ${ }^{82}$ Period-like domain (PER): a non-described region involved in protein-protein interactions. Leucine zipper (LZ): a hydrophobic motif usually found in transcription factors. It is involved in formation of protein dimers. Nuclear localization signal (NLS): a putative arginine-rich nuclear localization signal. PDZ-I: a short C-terminal amino-acidic sequence matching the consensus of class-I PDZ-binding peptides ${ }^{83}$

theoretically expressed (Figure 1). To date, only limited information is available on expression and function of hDAB2IP isoforms, with most functional studies performed with isoform 2.

In humans, DAB2IP mRNA is detected in most tissues and organs, but is very low or absent in blood cells. A study of fetal tissue arrays by immunohistochemistry indicates that DAB2IP is expressed in most tissues, with gestational age- and tissue-specific patterns. ${ }^{3}$ However, DAB2IP knockout $(\mathrm{KO})$ mice are viable and develop normally, arguing against a major role of this protein in embryogenesis and differentiation. ${ }^{4,5}$

Regarding its mechanism of action, DAB2IP has an enzymatic activity whose core lies in the Ras-GAP domain. In addition, DAB2IP acts as an adaptor, or scaffold, in protein complexes relevant for signal transduction, and it can function as a competitor, or scavenger, by binding signaling proteins and preventing their interaction with upstream activators, or downstream effectors (Table 1). Through these actions, DAB2IP has the potential to modulate a remarkable array of cancer-related pathways, ${ }^{6,7}$ summarized below.
RAS-dependent signaling. Ras proteins are monomeric GTPases strongly involved in cancer. Physiological or oncogenic activation of Ras induces a wide range of downstream effects; the best characterized is the RAF-MEK-ERK cascade, affecting cell growth, proliferation, survival, and differentiation. ${ }^{8,9}$ In addition, Ras proteins can also activate $\mathrm{PI} 3 \mathrm{~K}$, mediating proliferative and survival signals. ${ }^{10,11}$

The GAP domain of DAB2IP is homologous to other RasGAPs, such as GAP120 and neurofibromin (NF1), and can stimulate the GTPase activity of RAS proteins both in vitro and in cancer cell lines (Figure 2). ${ }^{12-15}$ In prostate cancer cells, DAB2IP was shown to be recruited by the adaptor protein DAB2/DOC2 to promote Ras inactivation and inhibition of MAPK signaling upon receptor stimulation. ${ }^{1}$ Through this activity, DAB2IP can also dampen Ras-induced activation of PI3K, contributing to inhibition of the PI3K-AKT signaling axis.

ASK1-JNK activation by TNF and other signals. ASK1 is a member of the MAP kinases (MAP3K) and is an upstream activator of c-Jun N-terminal kinase (JNK) and p38 MAPK. ${ }^{16}$ 
Table 1 A list of published DAB2IP interactions and their functional impact

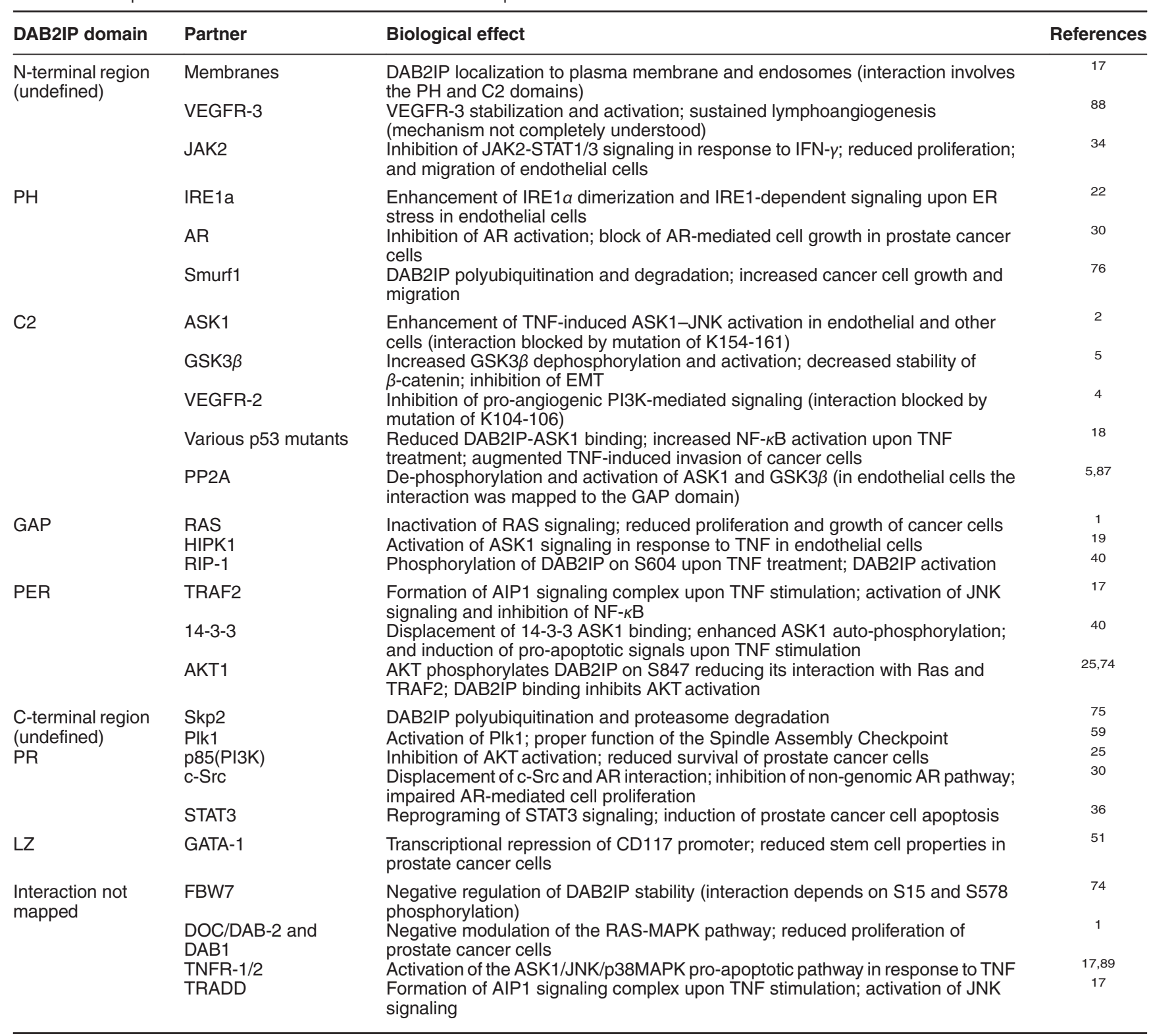

ASK1 is activated in response to various signals, including pro-apoptotic stimuli and pro-inflammatory cytokines, in particular tumor necrosis factor alpha (TNFa). ${ }^{16}$ DAB2IP drives the response to TNFa toward TRAF2-dependent ASK1-JNK/p38 MAPK activation, while indirectly inhibiting the NF- $k \mathrm{~B}$ branch $^{17}$ (Figure 3 ). This model is well characterized in endothelial cells, but is conserved in other cell types, including cancer cells. ${ }^{15,18}$ In TNF-treated cells, DAB2IP can likewise support ASK1-JNK activation by the pro-apoptotic kinase Homeodomain-interacting protein kinase 1 (HIPK1). ${ }^{19}$

Notably, DAB2IP also mediates ASK1-JNK activation upon endoplasmic reticulum (ER) stress (Figure 4a). Accumulation of unfolded proteins in the ER triggers a stress response called UPR (unfolded protein response), initiated by three receptors: ATF6 (activating transcription factor 6), PERK (PKR-like ER kinase), and IRE1a (inositol-requiring enzyme-1). ${ }^{20,21}$ In particular, IRE1a is a ser/thr kinase with ribonuclease activity; when activated, it catalyzes cytoplasmic splicing of the mRNA encoding Xbp1 (X-box-binding protein 1), generating the transcription factor Xbp1s, which upregulates UPR genes. At the same time, IRE1a can trigger pro-apoptotic JNK signaling through recruitment of the TRAF2-ASK1 complex. ${ }^{20}$ DAB2IP binds IRE1a, and was shown to be required for activation of this signaling cascade in endothelial cells. ${ }^{22}$ Cancer cells suffer ER stress due to expression of mutant proteins, and the effects of hypoxia, inflammation, and chemotherapy. ${ }^{21}$ The UPR can support cell survival and adaptation, but can also induce apoptosis; in this context, the role of DAB2IP in 


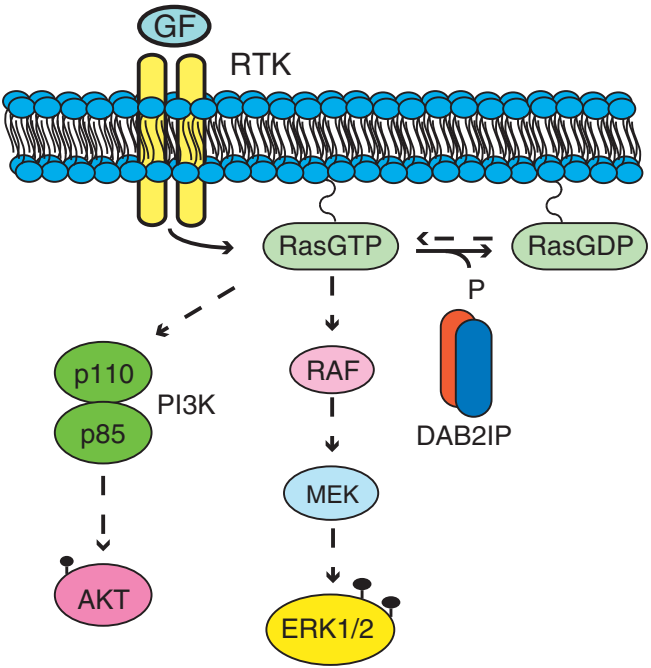

Figure 2 DAB2IP inhibits RAS-dependent signaling. DAB2IP is able to stimulate in vitro and in vivo the GTPase activity of RAS proteins (H-Ras, K-Ras, and N-Ras) facilitating GTP hydrolysis to GDP. As a RAS-GAP, DAB2IP negatively controls activation of MAP kinases in response to exogenous stimuli (i.e., EGF, epidermal growth factor) and operates to finely orchestrate proliferation and differentiation of normal and cancer cells. ${ }^{12-15}$ As a RAS-GAP, DAB2IP can also inhibit RAS-dependent activation of the PI3K-AKT pathway

promoting IRE1-induced activation of the ASK1-JNK axis might have a tumor-suppressive function that awaits characterization.

PI3K-AKT signaling. The PI3K (phosphoinositide 3-kinase)AKT axis has an impact on cell metabolism, size, proliferation, survival, and motility, ${ }^{23}$ and is frequently activated in cancer either by gain-of-function mutations or by loss of function of the critical regulator PTEN. ${ }^{24}$ DAB2IP inhibits the PI3K-AKT axis by directly interacting with both proteins, reducing phosphorylation and activation of $\mathrm{AKT}^{25}$ (Figure 4b). The GAP activity of DAB2IP can further enforce inhibition of the $\mathrm{PI}$ KK-AKT axis by reducing Ras-dependent activation of PI3K p110a subunit. ${ }^{10,11}$

Interestingly, animal models showed that DAB2IP functions as endogenous inhibitor of adaptive angiogenesis in part by binding directly to VEGFR-2 and limiting PI3K activation (Figure 4b). ${ }^{4}$

GSK3 $\boldsymbol{\beta}-\boldsymbol{\beta}$-catenin signaling. GSK3 $\beta$ is a ser/thr kinase that phosphorylates numerous substrates, often triggering their degradation. Signaling cascades such as Wnt/ $\beta$-catenin and PI3K-AKT promote its inactivation through Serine 9 phosphorylation. In canonical WNT signaling, inhibition of GSK3 $\beta$ leads to stabilization of $\beta$-catenin. ${ }^{26}$ In various cell models, DAB2IP was shown to support GSK3 $\beta$ activation, counteracting WNT signals (Figure 4c). ${ }^{5}$ Notably, GSK3 $\beta$ controls other key signaling proteins, for instance, Hedgehog effectors Gli and SUFU; ${ }^{27,28}$ it is possible that DAB2IP may influence additional pathways involving GSK3 $\beta$.

Androgen receptor signaling. The androgen receptor (AR) regulates normal prostate development as well as proliferation and survival of prostate carcinoma. ${ }^{29}$ DAB2IP can inhibit
AR-mediated cell proliferation via multiple mechanisms (Figure 4d): it binds directly the AR to suppress its phosphorylation and nuclear translocation; it prevents $A R$ interaction with the kinase c-src, blocking the so-called non-genomic pathway; ${ }^{30}$ and it counteracts androgenindependent AR activation induced by Wnt signaling. ${ }^{30}$ Thus, DAB2IP is a unique intrinsic negative modulator of AR activity in normal and transformed prostate cells. ${ }^{31}$

JAK-STAT signaling. The JAK-STAT pathway is involved in embryonic development, stem cell maintenance, and inflammation; aberrant activation of STATs (signal transducer and activator of transcription) can increase tumor cell proliferation and invasion, and suppress antitumor immunity. ${ }^{32}$ DAB2IP was shown to limit JAK-dependent STAT1/3 and PI3K-Akt activation by interferon gamma (Figure $4 e$ ), reducing proliferation and migration of vascular smooth muscle cells during neo-intima formation. ${ }^{33,34}$ In non-muscle invasive bladder cancer, DAB2IP-dependent inhibition of STAT3 has been reported to limit expression of Twist1 and P-glycoprotein, crucial factors for chemoresistance. ${ }^{35}$ In prostate cancer cells, DAB2IP was found to directly bind STAT3, suppressing transactivation and expression of the anti-apoptotic target survivin. ${ }^{36}$ It is highly plausible that DAB2IP can negatively regulate activation of STAT3 in other cell types, with implications for additional tumor conditions.

\section{DAB2IP Inactivation Fosters Tumor Progression}

Although DAB2IP can dampen multiple oncogenic pathways, $\mathrm{DAB} 2 \mathrm{IP} \mathrm{KO}$ mice do not display increased incidence of spontaneous tumors. However, these animals have phenotypes related to cancer formation or progression, such as increased proliferation of the prostate epithelium, ${ }^{37}$ dysplasia of the colon epithelium, ${ }^{38}$ and augmented inflammatory

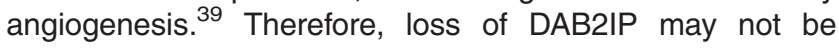
sufficient to induce cancer formation, but can unleash the oncogenic potential of multiple extracellular signals, promoting tumor progression and aggressiveness.

Loss of DAB2IP increases cancer cell proliferation and survival. Augmented cell proliferation has been correlated to abrogation of DAB2IP functions in various cultured cell lines and in vivo models, and has been linked to loss of Ras-GAP activity and hyperactivation of AKT. ${ }^{12,15,25}$ Mice injected with $\mathrm{PCa}$ cells overexpressing $\mathrm{H}-\mathrm{Ras}$, or depleted for DAB2IP, developed highly proliferative tumors with similar kinetics and maximum size. ${ }^{15}$ In this model, wild-type DAB2IP significantly blocked tumor development, whereas expression of a catalytically inactive GAP mutant (DAB2IP-R289L) was ineffective. ${ }^{15}$ Tumors formed by DAB2IP-depleted PCa cells also display PI3K-AKT pathway activation. ${ }^{25}$ Indeed, sustained AKT activation characterizes the hyperplastic prostate epithelium of DAB2IP KO mice. ${ }^{25}$ Regarding survival, a clear decrease in apoptosis has been appreciated in various models of DAB2IP downregulation; this may reflect less efficient ASK1 activation by pro-apoptotic signals, or constitutive AKT activation. ${ }^{17,22,25,40}$ Similarly, prolonged Ras activity in DAB2IP-depleted cells may increase cell 


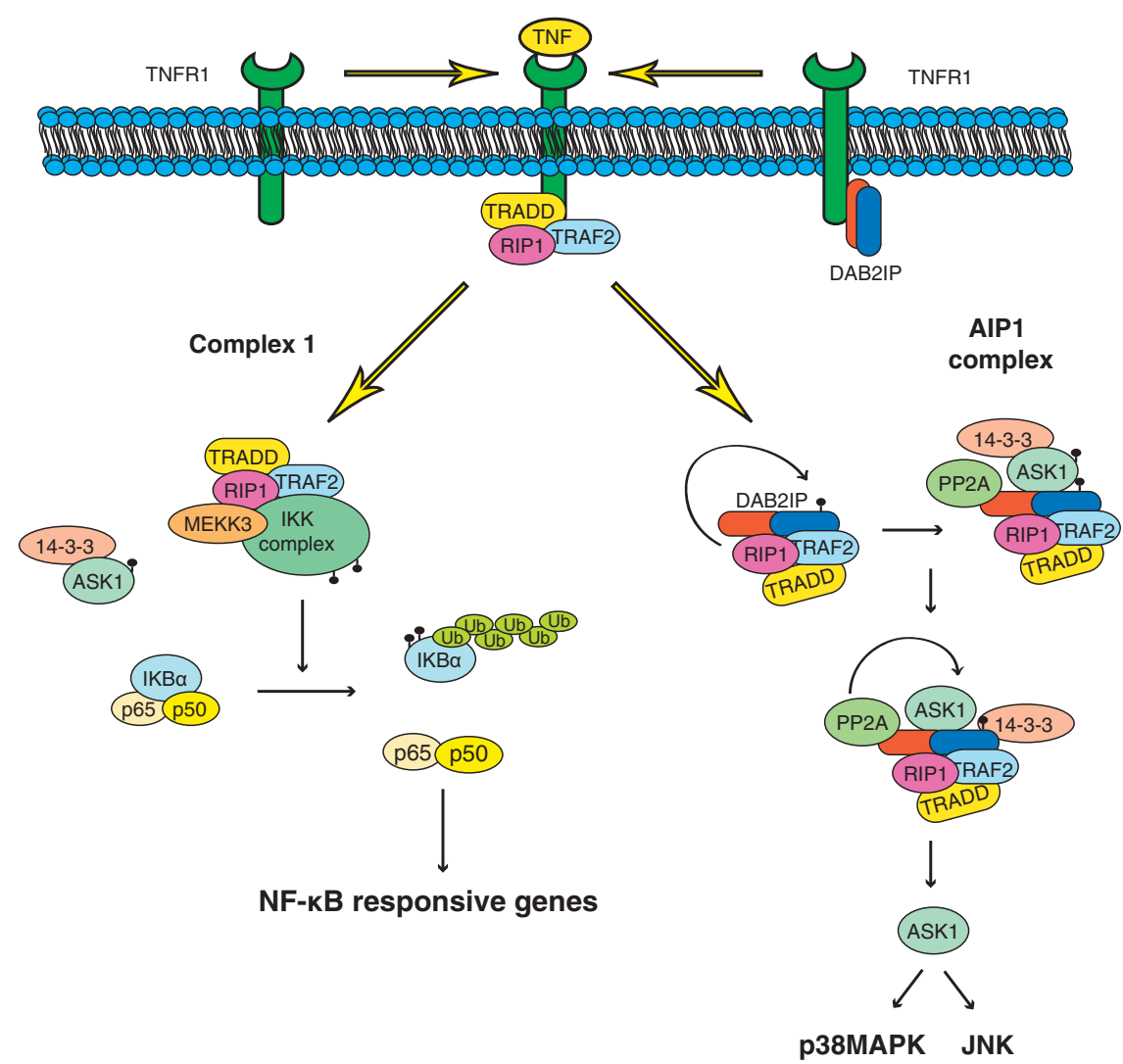

Figure 3 DAB2IP in TNF $\alpha$ signaling: activation of ASK1/JNK. Tumor necrosis factor alpha can trigger cell death or induce NF- $\kappa$ B-mediated transcription of inflammatory, prosurvival, and pro-invasive genes. This pathway is initiated by the recruitment of adaptor protein TRADD (TNFR-associated death domain protein), serine-threonine kinase RIP1 (receptor-interacting protein-1), and TRAF2 to the intracellular domain of the activated TNFR1 (TNF receptor 1). This complex recruits and activates the multisubunit kinase IKK, responsible for the inhibitory phosphorylation of $I_{k} B$. It has been demonstrated that RIP1 activates the IKKs indirectly via MEKK3. Once phosphorylated, IKB undergoes polyubiquitination and degradation, releasing p65/p50 NF- $\mathrm{BB}$ from its inhibitory binding, and leading to transcriptional activation. ${ }^{84,85}$ Ligand-bound TNFR1 can also catalyze formation of a multiprotein complex that recruits and activates ASK1 (apoptosis signal-regulating kinase), leading to activation of the pro-apoptotic JNK and p38 MAP kinases ${ }^{86}$ DAB2IP promotes TNF-induced activation of the ASK1-JNK axis by sequestering TRAF2 from the NF- $K B$-activating complex, driving formation of the so-called AIP1 complex. ${ }^{17}$ DAB2IP binds membrane phospholipids through its PH/C2 domain in a closed and inactive conformation; upon TNF stimulation, RIP1 phosphorylates DAB2IP on Serine 604, inducing a conformational switch that allows formation of the complex. DAB2IP then displaces the inhibitory binding between ASK1 and 14-3-3 protein, favoring ASK1 activation. ${ }^{40}$ DAB2IP also mediates recruitment of PP2A to ASK1, binding both proteins through its C2 domain; this favors removal of the inhibitory S967 phosphorylation and further activation of $A S K 1^{87}$

survival via both the Ras-ERK-MAPK and the Ras-PI3KAKT pathways. ${ }^{9,12,15,25}$

Loss of DAB2IP promotes cell migration and metastasis. DAB2IP levels have been inversely correlated with expression of epithelial to mesenchymal transition (EMT) markers in melanoma, bladder, prostate, colorectal, and breast cancer. ${ }^{5,15,41-45}$ In line with these observations, DAB2IP KO mice have dilated colonic crypts with altered epithelium, ${ }^{45}$ and have mesenchymal features in the prostate gland epithelium. $^{5}$

Experimental DAB2IP loss initiates EMT in normal prostate epithelial cells and prostate carcinoma cell lines, $5,15,43$ and promotes dissemination of tumor cells in cancer xenografts..$^{5,15,41,45}$ In contrast, an increase in DAB2IP levels reverts EMT features in metastatic prostate and colorectal cancer (CRC) cells. ${ }^{5,15}$ DAB2IP may control EMT and cell invasion by coordinating both the WNT/ $\beta$-catenin and NF- $K B$ pathways. Cells from DAB2IP ${ }^{-1-}$ mice have increased GSK3 $\beta$ phosphorylation, and $\beta$-catenin overexpression is sufficient to overcome DAB2IP-mediated inhibition of cell migration and invasion. ${ }^{5}$ A point mutation on $\mathrm{S} 604$, which blocks TRAF2 binding but leaves untouched the GAP activity, renders DAB2IP incapable to suppress xenograft dissemination in vivo, proving that $\mathrm{NF}-k \mathrm{~B}$ inhibition has a major role in preventing metastasis. ${ }^{15,45}$ Notably, a catalytically inactive GAP mutant (DAB2IP-R289L), still capable of inhibiting $\mathrm{NF}-\kappa \mathrm{B}$, only partially suppresses metastasis in the same model, ${ }^{15}$ supporting the notion that Ras inhibition by DAB2IP also has a role in this context. Indeed, Ras hyperactivation can increase cell motility by regulating TGF- $\beta$ signaling, destabilizing $\mathrm{E}$-cadherin/ $\beta$-catenin complexes, and affecting cytoskeletal dynamics. ${ }^{9,46}$

Recent studies suggest an additional mechanism by which DAB2IP inactivation can favor metastasis: in prostate cancer cells loss of DAB2IP correlated with accumulation and activation of Hypoxia-inducible factor 1 (HIF-1a), a key inducer of EMT and cell motility. ${ }^{47}$ Similarly, increased HIF-1a and VEGF were observed upon DAB2IP KO in human endothelial cells. $^{48}$ Finally, DAB2IP ablation was shown to induce 

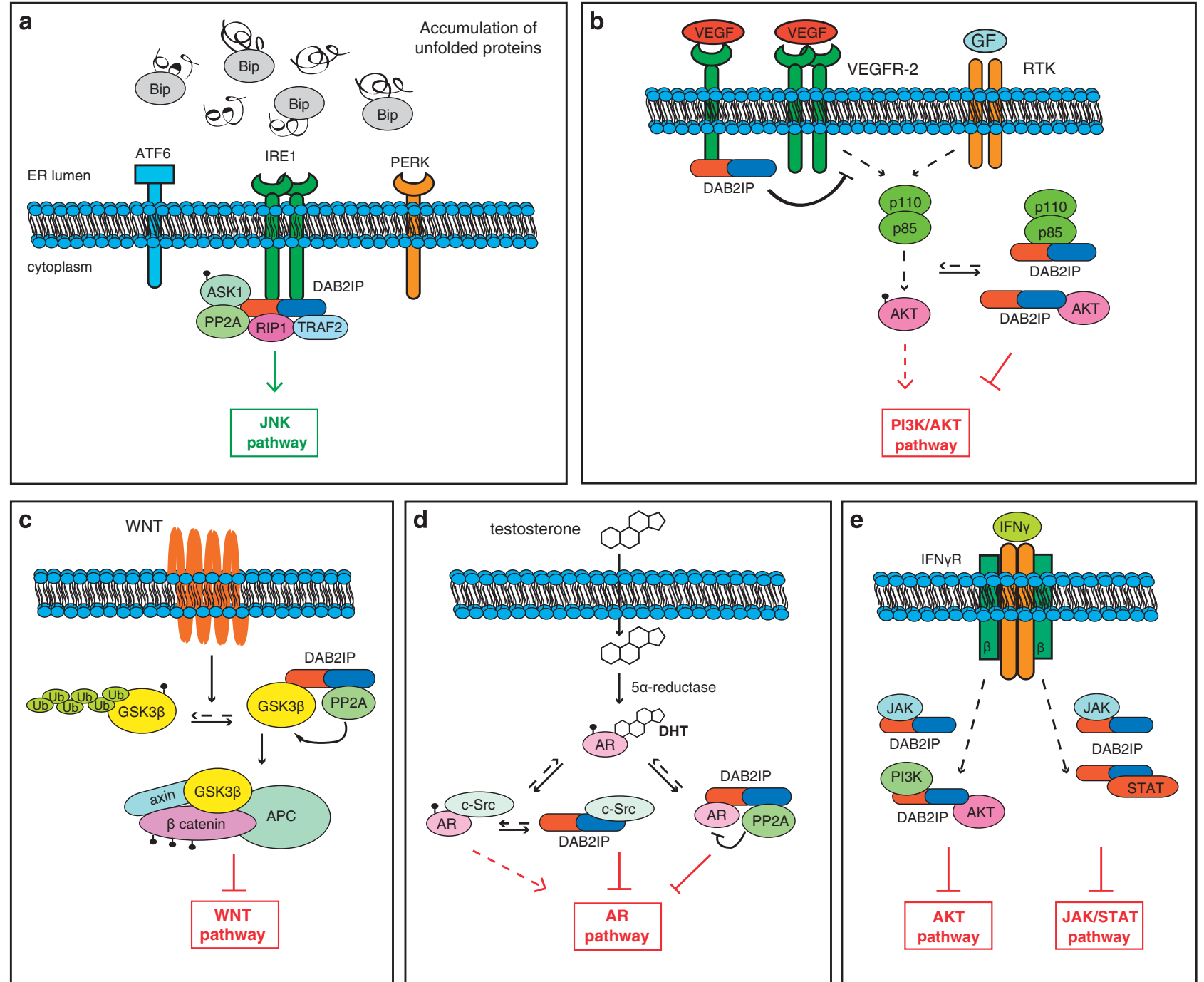

Figure 4 DAB2IP modulates multiple signaling pathways. (a) Unfolded protein response. DAB2IP binds the cytoplasmic domain of the IRE1 $\alpha$ receptor, a sensor of ER stress. Accumulation of unfolded proteins in the ER titrates the endoplasmic chaperone BiP (GRP78) resulting in IRE1 $\alpha$ dimerization and activation. DAB2IP facilitates IRE1 $\alpha$ activation, and participates in a signaling complex required to induce TRAF2-dependent ASK1 activation and JNK phosphorylation. ${ }^{22}$ (b) PI3K-AKT signaling. DAB2IP binds the p85 subunit of PI3K through its PR domain and prevents PI3K-p85 relocation from the cytoplasm to the membrane, a necessary step for PI3K activation and signaling to AKT. Notably, DAB2IP reinforces this inhibitory effect by directly binding $A K{ }^{25}{ }^{25}$ In endothelial cells, DAB2IP interacts with the cytoplasmic domain of VEGFR-2 counteracting VEGF-induced signal transduction. ${ }^{4}$ (c) WNT/GSK3 $\beta / \beta$-catenin signaling. DAB2IP interacts via its $\mathrm{C} 2$ domain with GSK3 $\beta$, recruiting phosphatase PP2A for S9 de-phosphorylation and leading to GSK3 $\beta$ activation. ${ }^{5}$ Once activated, GSK3 $\beta$ phosphorylates numerous substrates, including $\beta$-catenin, promoting their proteasomal degradation. ${ }^{5}$ (d) AR signaling. DAB2IP acts as a scaffold protein for PP2A to suppress DHT-elicited S81 phosphorylation of the AR, preventing its nuclear translocation and binding to androgen response elements. In addition, DAB2IP can compete with the AR for binding to c-Src, thus blocking the non-genomic AR pathway. ${ }^{30}$ (e) JAK-STAT signaling. In vascular smooth muscle cells (VSMCs) treated with IFN- $\gamma$, DAB2IP directly binds to JAK2 and inhibits its kinase activity, limiting JAK-dependent STAT1/3 and PI3K-AKT phosphorylation and activation. ${ }^{33}$ DAB2IP also binds directly STAT3, inhibiting its transactivating function ${ }^{36}$

expression of HIF-2a in renal cell carcinoma cells. ${ }^{49}$ Therefore, DAB2IP inactivation may promote an hypoxia-like response, with upregulation of HIF target genes and increased expression and activity of VEGF proteins, affecting the cancer cell and its microenvironment, and promoting tumor vascularization.

Loss of DAB2IP promotes expansion of cancer stem cells. Cancer stem cells (CSCs) have been proposed as driving force of tumorigenesis and the seed of metastases. ${ }^{50}$ A recent study reported that DAB2IP suppresses transcription of stem cell factor receptor CD117, by interacting with
GATA-1 on a silencer element on its gene. ${ }^{51} \mathrm{Up}$ to now, this is the first-and only-evidence of a nuclear function for DAB2IP: it would be interesting to define whether such localization is dependent on a functional NLS, or is restricted to a specific DAB2IP isoform. Through inhibition of PI3K-AKT signaling, DAB2IP also represses ZEB1, another CSC determinant. $^{51}$ In line with these observations, DAB2IP KO prostate cancer cells have increased sphere-formation activity in vitro, and tumorigenic potential in mice. ${ }^{51}$

Another study reported that DAB2IP-mediated inhibition of NF- $\kappa B$ can suppress CSC features in human CRC, as DAB2IP depletion in CRC cells increased sphere formation in soft agar 


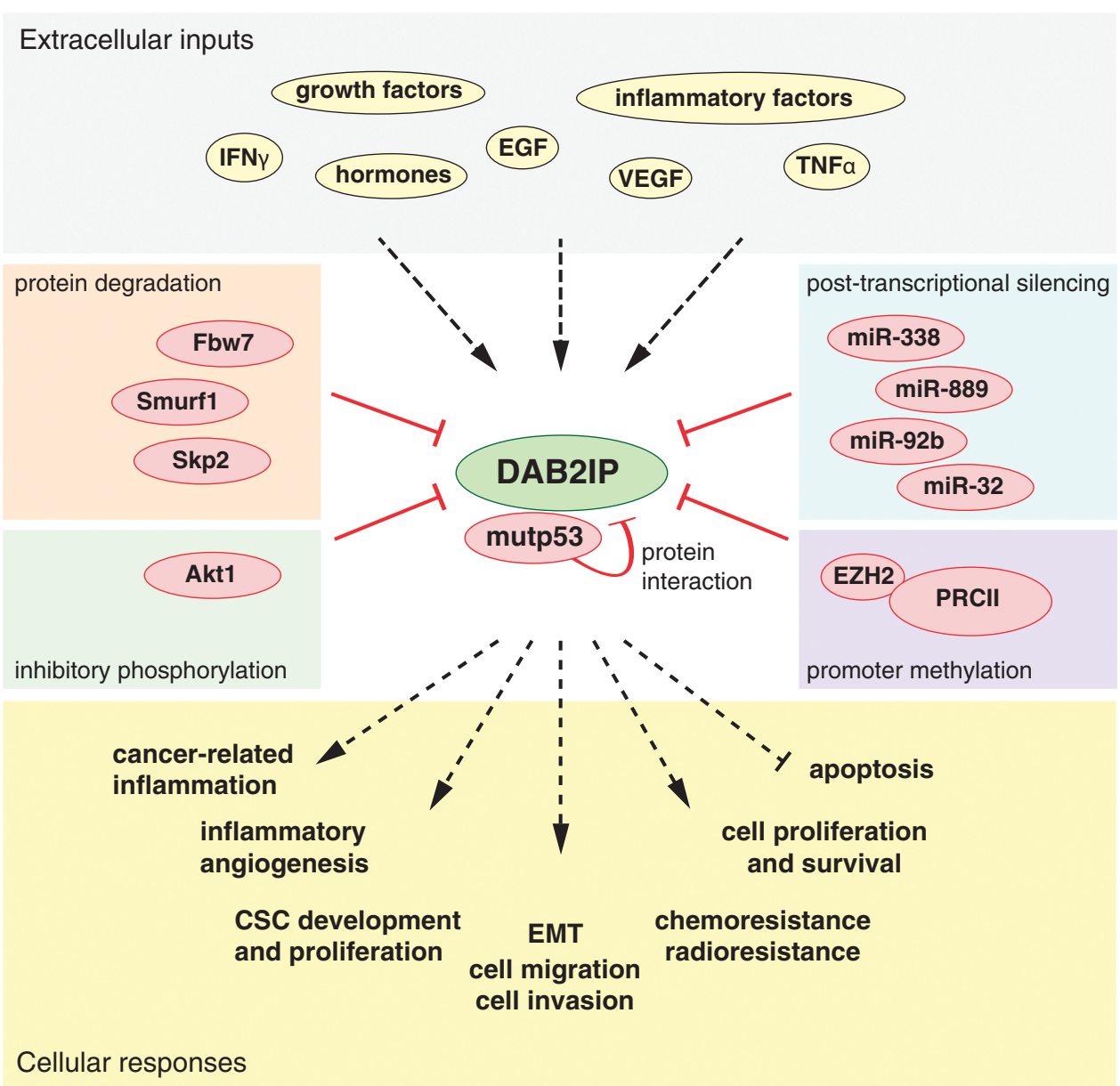

Figure 5 DAB2IP inactivation mediated by various mechanisms promotes oncogenic responses to multiple extracellular inputs. DAB2IP affects the cancer cells' response to inflammatory cytokines, growth factors, and hormones secreted in the tumor microenvironment by stromal, immune, and tumor cells. DAB2IP is frequently inactivated by epigenetic or post-transcriptional means in human malignancies. Epigenetic DAB2IP inactivation relies on promoter hypermethylation mediated by the EZH2-PRC2 complex. Various microRNAs have been described that can target the DAB2IP 3' UTR reducing protein expression. Direct binding with p53 mutant proteins interferes with other DAB2IP interactions. DAB2IP protein levels can be negatively regulated by the activity of the E3-ubiquitin ligases Fbw7, Skp2, and Smurf1. Phosphorylation by Akt1 can also inhibit DAB2IP functions. DAB2IP inactivation promotes tumor growth and survival, development, and proliferation of CSC, and resistance to chemo- and radiotherapy. It induces EMT, increases cell migration and invasion, and counteracts pro-apoptotic signaling. Finally, DAB2IP inactivation may also have an impact on tumor-related inflammation

and expression of EMT and stem cell markers. ${ }^{45}$ Accordingly, in CRC patients reduced DAB2IP levels correlate with increased number of CD133-positive cells (stem cell marker) and faster tumor progression. ${ }^{45}$

DAB2IP inactivation fosters an inflammatory microenvironment. Inflammation has a crucial role in cancer development and progression, affecting also metastasis and response to therapy. ${ }^{52,53}$ Given its inhibitory role on VEGF, NF- $k$ B, and STAT3 pathways, DAB2IP functions as an anti-inflammatory protein, especially in vascular endothelial cells. Indeed, DAB2IP-/- mice show enhanced inflammation in models of ischemic hind limb, graft arteriosclerosis, and inflammatory angiogenesis. ${ }^{4,33,34,54}$ In hyperlipidemic $\mathrm{ApoE}^{-/-}$mice, DAB2IP KO increases secretion of inflammatory cytokines and augments macrophage infiltration, thereby inducing endothelial dysfunction and early phases of atherosclerosis. ${ }^{54}$

Notably, vascular endothelial-specific depletion of DAB2IP promotes tumor growth and dissemination in melanoma and breast cancer mouse models, favoring establishment of a prometastatic microenvironment. ${ }^{44}$ This observation is based on experimental tissue-specific DAB2IP KO; it will be interesting to explore whether cancer cells may devise mechanisms to induce DAB2IP downregulation in endothelial or stromal cells.

DAB2IP controls signal transduction in response to multiple cytokines, including TNF $\alpha$, IFN- $\gamma$, TLR4, and IL- $1 \beta$; therefore, it may significantly have an impact on the behavior of cancer cells in an inflammatory microenvironment. 2,18,34,55 For instance, TNFa induces invasion in DAB2IP-inactivated breast cancer cells, triggering upregulation of a subset of NF- $k \mathrm{~B}$ and ASK1/JNK target genes enriched in matrix-remodeling enzymes and chemokines. Intriguingly, such response can also recruit cytotoxic immune cells, potentially affecting tumor progression and prognosis. ${ }^{18}$ Various lines of evidence correlate Ras activation in cancer cells with a compromised host immune response and recruitment of suppressive regulatory $\mathrm{T}$ cells; ${ }^{9}$ in this perspective, loss of DAB2IPdependent RAS-GAP activity may favor tumor escape from 
the immune system. We still have an incomplete understanding of the role of DAB2IP in modulating the inflammatory component of the tumor microenvironment, and this aspect deserves further investigation.

Loss of DAB2IP confers resistance to chemo- and radiotherapy. Resistance to therapy is a significant barrier to cure cancer. Multiple molecular mechanisms are involved in chemo- and radioresistance, and the microenvironment can also influence cancer response to drugs. DAB2IP loss correlates with more efficient DNA repair, resistance to apoptosis, and robust cell cycle checkpoints in prostate cancer cells exposed to ionizing radiation. ${ }^{56}$ Interestingly, DAB2IP-depleted cells have increased mTOR-S6K pathway activation and significantly more autophagy, suggesting that in normal cells DAB2IP inhibits autophagy, and loss of such inhibition in cancer contributes to radiation resistance. ${ }^{57}$

DAB2IP loss in prostate cancer cells was also shown to enhance chemoresistance by upregulation of the antiapoptotic protein clusterin. ${ }^{58}$ Similarly, by augmenting STAT3 activation and survivin expression, loss of DAB2IP facilitates survival of prostate cancer cells after androgen deprivation therapy. ${ }^{36}$

Very recently, it has been reported that DAB2IP depletion causes defects in microtubule-kinetochore attachment, increasing the frequency of aberrant mitoses in prostate cancer cell lines. In line with these observations, MEFs from DAB2IP KO mice display aneuploidy. ${ }^{59}$ Authors showed that DAB2IP interacts with the kinase Plk1, facilitating its activation and phosphorylation of the checkpoint kinase BubR1. Importantly, DAB2IP-depleted cells have a defective spindle assembly checkpoint. ${ }^{59}$ This phenotype requires careful consideration, as DAB2IP status may influence the response to microtubule-targeting drugs used in cancer therapy.

\section{Cancer Cells Adopt Multiple Strategies to Block DAB2IP Functions}

Despite its tumor-suppressive function, DAB2IP is rarely mutated in human cancers. A consistent body of literature reports epigenetic inactivation of DAB2IP by promoter methylation in tumors and tumor-derived cell lines (see below). More recently, other mechanisms for DAB2IP inactivation in cancer have been described, uncovering an interesting scenario where tumor cells arising with disparate genetic backgrounds may devise different means to disable this single modulator of multiple signaling pathways (Figure 5).

Transcriptional silencing by promoter methylation. A number of studies have described aberrant methylation of the DAB2IP gene in lung, breast, prostate, and gastrointestinal cancer. ${ }^{60-63}$ These studies focused on a $\mathrm{CpG}$ island partially overlapping exon 3 , which contains a functional promoter and TSS. Transcripts originating at this TSS are spliced to exon 4 and are predicted to encode the shortest DAB2IP protein isoform (Figure 1). Published studies provide compelling evidence that methylation of this region correlates with reduced DAB2IP expression in tumor tissues and cell lines, despite the presence of at least two additional TSSs located, respectively, 130 and $48 \mathrm{kbp}$ upstream, and other functional TSSs further downstream. ${ }^{60-65}$ It is possible that methylation of this region is sufficient to turn the gene off; alternatively, other sites may be coordinately methylated for efficient DAB2IP silencing. Three additional CpG islands are mapped in the $h D A B 2 I P$ gene, in some cases corresponding to functional TSSs; little is currently known about the methylation status of these regions in normal or pathological conditions, or its potential impact on DAB2IP transcription.

Recently, an overview of data from the cancer genome atlas uncovered a CpG site whose methylation status correlates inversely with DAB2IP expression and patient survival in renal cell carcinoma. ${ }^{66}$ Curiously, this site is located outside major $\mathrm{CpG}$ islands, suggesting further complexity in this regulation.

The main factor controlling DAB2IP gene methylation appears to be the PRC2 (polycomb-repressive complex-2)$\mathrm{EZH} 2$ (Enhancer of Zeste homolog) complex. ${ }^{65} \mathrm{EZH} 2$ is a histone lysine $\mathrm{N}$-methyltransferase that catalyzes trimethylation of H3K27, and is frequently overexpressed in cancer. ${ }^{67} \mathrm{~A}$ clear inverse correlation between EZH2 and DAB2IP expression in tumors has been reported in multiple studies, and overexpression of EZH2 reduces DAB2IP mRNA and protein levels in cancer cells. ${ }^{15,65}$

Molecular studies on the TSS in exon 3 confirmed that high levels of di- and tri-methyl H3-Lys27 in this region are directly modulated by $\mathrm{EZH} 2$, leading to recruitment of the PRC2 protein complex and histone deacetylases HDAC1/2. ${ }^{42,65,68}$ In line with methylation-driven epigenetic silencing, treatment with 5'-aza-cytidine and Trichostatin A cooperatively increased DAB2IP expression in cancer cell lines. ${ }^{60}$

Recently, it has been reported that the transcription factor Snail can repress DAB2IP expression in colon cancer cells. A co-repressor complex containing Snail, EZH2, and HDAC1/2 was detected on the DAB2IP promoter. ${ }^{42}$ Interestingly, GSK3 $\beta$ phosphorylates Snail to limit its stability and activity in epithelial cells; as DAB2IP is a positive modulator of GSK3 $\beta$, epigenetic downregulation of DAB2IP by Snail defines a regulatory feedback that may have an impact on EMT and metastasis. $^{42}$

Post-transcriptional repression by microRNAs. DAB2IP has a relatively long $3^{\prime}$ UTR sequence, and is therefore a good candidate for post-transcriptional silencing by microRNAs (miRNAs). Up to now, four studies have described miRNAs that are able to target DAB2IP.

miR-338 was reported to reduce DAB2IP levels in neurons. ${ }^{69}$ miR-338 is located within an intron of the Apoptosis-Associated Tyrosine Kinase (AATK) gene, and cooperates with AATK to induce neuronal differentiation by suppressing a group of target mRNAs encoding negative regulators of neurite growth and neural differentiation, including DAB2IP. Authors provide convincing evidence that miR-338 can downregulate DAB2IP, but do not explore the role of DAB2IP repression in neuronal differentiation, nor the potential implications of such regulation in cancer. ${ }^{69}$

miR-889 was reported to downregulate DAB2IP protein levels in two esophageal squamous cell carcinoma (ESCC) cell lines, and to promote cell proliferation in in vitro and in vivo experiments. $^{70}$ Intriguingly, DAB2IP overexpression can subvert miR-889-induced proliferation phenotype, and DAB2IP depletion by siRNA recapitulates the effects of 
miR-889 on ESCC cell proliferation. Finally, in a set of ESCC clinical samples, the levels of miRNA-889 and DAB2IP were found to be inversely correlated. ${ }^{70}$ Although authors confirmed that miR-889 targets DAB2IP 3' UTR sequences, they provided no formal demonstration that the effects of miR-889 in ESCC cells are mediated by DAB2IP silencing. The proliferation phenotype is coherent with DAB2IP depletion; it would be interesting to test the impact of miR-889 on cell migration and invasion.

The oncogenic miR-32 was shown to target DAB2IP in prostate cancer cell lines. ${ }^{71}$ The authors demonstrated that cells overexpressing miR-32 have lower DAB2IP protein levels, activate expression of autophagy markers, and become more resistant to ionizing radiation and to Brefeldin-induced apoptosis. ${ }^{71}$ Also in this case, there is no formal proof that the effects of miR-32 overexpression are mediated by DAB2IP depletion, but the phenotype is coherent with loss of DAB2IP function.

Finally, a very recent report showed that miR-92b can target the 3' UTR of DAB2IP, increasing migration and expression of EMT markers in a bladder cancer cell line. ${ }^{72}$

Together, these studies confirm that DAB2IP is a target of miRNA-mediated repression, and offer a glimpse of the far-reaching impact that this kind of regulation may have in cancer progression. ${ }^{73}$

Ubiquitin-mediated degradation. Recent studies have begun to shed light on the regulation of DAB2IP turnover, identifying E3 ubiquitin ligases that can promote its degradation.

Inuzuka and colleagues ${ }^{74}$ observed that FBW7-SCF complexes can bind and degrade DAB2IP. Two putative phosphodegron sequences have been identified in DAB2IP, both required for efficient interaction with FBW7. On the basis of depletion and overexpression experiments, authors reported that DAB2IP stability is affected by casein kinase 1 delta possibly through phosphorylation of these serines. ${ }^{74}$

A second study showed that DAB2IP is polyubiquitinated and degraded by Skp2-SCF complexes in prostate cancer cell lines. Authors identified lysines required for ubiquitination, but reported no evidence for phosphorylation-mediated degradation. ${ }^{75}$ Interestingly, in prostate cancer cells DAB2IP overexpression can reduce Skp2 levels, most likely by inhibition of AKT. Although an inverse correlation between the two proteins has not been clearly demonstrated, a reciprocal regulation between DAB2IP and Skp2 may be relevant in some cancers. ${ }^{75}$

Recently, North and colleagues ${ }^{76}$ reported that DAB2IP is bound and degraded by the Nedd4-related E3 ligase Smurf1. Smurf1 binds the N-terminal domain of DAB2IP to promote its degradation. Similar to Skp2, Smurf1 is stabilized by AKTdependent phosphorylation, so that aberrant AKT activation can reduce DAB2IP protein levels by increasing Smurf1. Interestingly, Smurf1 depletion reduced proliferation and invasion of prostate and breast cancer cells, and this effect could be rescued by DAB2IP KO; this suggests that Smurf1 oncogenic activity is mediated, at least in part, by DAB2IP destabilization. ${ }^{76}$

Up to now, no studies have systematically explored DAB2IP protein stability under physiological and pathological conditions; it is plausible that other ubiquitin ligases are involved in its turnover.

Post-translational modifications: phosphorylation by Akt. DAB2IP can be phosphorylated by RIP1 on Ser 604 within the PER domain, and by AKT1 on Ser 847 within the proline-rich domain. Although RIP1-mediated phosphorylation is stimulatory, ${ }^{40}$ a recent study reported that AKT-mediated phosphorylation inhibits DAB2IP functions: in transient overexpression experiments, mutation of serine 847 to aspartic (to mimic constitutive phosphorylation) reduced DAB2IP interaction with Ras and TRAF2, with no effect on Ras-dependent $p$-ERK levels. ${ }^{74}$ Accordingly, mutation to alanine increased DAB2IP interaction with both proteins, suggesting that $\$ 847$ phosphorylation can interfere with DAB2IP activity. ${ }^{74}$ Intriguingly, these data suggest a reciprocal regulatory feedback loop, whereby DAB2IP inhibits AKT activation, whereas AKT inhibits DAB2IP directly by phosphorylation, and indirectly by stabilization of Smurf1 and Skp2 (see above). Additional studies are required to confirm and extend these observations, and to determine whether S847 phosphorylation might affect other important DAB2IP functions-first of all modulation of ASK1 and NF- $\kappa \mathrm{B}$ signaling.

Interaction with mutant p53. DAB2IP can be bound and functionally inhibited by mutant p53 in the cytoplasm of cancer cells. TP53 is probably the most frequently mutated tumor suppressor gene; $\sim 75 \%$ of the mutations are missense substitutions, and p53 missense mutants (mutp53) acquire oncogenic properties - a phenomenon defined as gain of function. We found that breast cancer cells expressing mutp53 undergo a pro-oncogenic response to inflammatory cytokines, in particular TNFa. ${ }^{18}$ Mechanistically, by binding DAB2IP mutp53 sustains TNF-induced activation of NF- $k$ B, counteracting the pro-apoptotic ASK1/JNK branch of the pathway. This results in a transcriptional program that promotes cell invasion and protects from cell death. Of note, expression of a decoy protein capable of interfering with DAB2IP-mutp53 interaction reduced tumor growth and metastasis in a mouse xenograft model. ${ }^{18}$ It is plausible that the mutp53-DAB2IP interaction has a broader impact in cancer progression, affecting the cancer cell's response to additional extrinsic inputs.

\section{Conclusions and Future Perspectives}

We have reviewed how DAB2IP can modulate the cytoplasmic events of major oncogenic pathways, and described the far-reaching impact that DAB2IP repression or inactivation can have on tumor progression. One concept we wish to emphasize is that by acting on multiple pathways DAB2IP can dampen pro-oncogenic signals originating from several different genetic mutations. This has two implications: first, DAB2IP inactivation is expected to favor progression of multiple different cancers. Second, DAB2IP reactivation could slow progression of cancers driven by different oncogenic alterations.

The first point is supported by the fact that DAB2IP expression or function is frequently compromised in cancer. 
In various studies, DAB2IP levels have been shown to stratify patients for response to therapy and overall survival, and its use as a prognostic marker is worth consideration. ${ }^{77,78}$ The second point is supported by solid lines of evidence that DAB2IP reactivation or overexpression can effectively reduce tumor growth, metastasis, and resistance to therapy in a variety of cell types. ${ }^{5,15,25,35,58}$

Considering that the DAB2IP gene is almost never mutated in cancer, its re-expression may be explored as a potential therapeutic strategy. For instance, in various types of cancer DAB2IP transcription is reduced by promoter methylation, but not totally abolished; its expression in these cells could be theoretically increased by acting at the post-transcriptional level. In addition, we found that DAB2IP can be partially blocked by interaction with cytoplasmic mutant p53; this effect appears to be stoichiometric, as displacing the mutp53-DAB2IP interaction, or overexpressing DAB2IP, restores tumor suppression. ${ }^{18}$ On the basis of these considerations, it is conceivable that increasing DAB2IP protein levels would be sufficient to reduce aggressiveness of tumors with or without mutant p53.

To conclude, we are convinced that this tumor suppressor gene bears a tremendous potential for molecular oncology, and we await with enthusiasm future discoveries on its function, regulation, and potential therapeutic manipulation.

\section{Conflict of Interest}

The authors declare no conflict of interest.

Acknowledgements. We thank G Del Sal and colleagues at LNCIB for comments and discussion. This work is supported by grants from AIRC (Italian Association for Cancer Research, IG 14173) and Università di Trieste (FRA 2014) to LC. AB is supported by the 'Guglielmina Lucatello e Gino Mazzega' postdoctoral fellowship from FIRC (Fondazione Italiana Ricerca sul Cancro).

1. Wang Z, Tseng CP, Pong RC, Chen H, McConnell JD, Navone $\mathrm{N}$ et al. The mechanism of growth-inhibitory effect of DOC-2/DAB2 in prostate cancer. Characterization of a novel GTPase-activating protein associated with $\mathrm{N}$-terminal domain of DOC-2/DAB2. J Biol Chem 2002; 277: 12622-12631.

2. Zhang R, He X, Liu W, Lu M, Hsieh JT, Min W. AIP1 mediates TNF-alpha-induced ASK1 activation by facilitating dissociation of ASK1 from its inhibitor 14-3-3. J Clin Invest 2003; 111 1933-1943.

3. Liu S, Zhu N, Chen H. Expression patterns of human DAB2IP protein in fetal tissues. Biotech Histochem 2012; 87: 350-359.

4. Zhang H, He Y, Dai S, Xu Z, Luo Y, Wan T et al. AIP1 functions as an endogenous inhibitor of VEGFR2-mediated signaling and inflammatory angiogenesis in mice. J Clin Invest 2008; 118: $3904-3916$

5. Xie D, Gore C, Liu J, Pong RC, Mason R, Hao G et al. Role of DAB2IP in modulating epithelial-to-mesenchymal transition and prostate cancer metastasis. Proc Natl Acad Sci USA 2010; 107: 2485-2490.

6. Liu L, Xu C, Hsieh J-T, Gong J, Xie D. DAB2IP in cancer. Oncotarget 2016; 7: 3766-3776.

7. Yun E-J, Wu K, Tsai Y-S, Xie D, Hsieh J-T. The functional role of DAB2IP, a homeostatic factor, in prostate cancer. In: Tindall DJ (ed). Prostate Cancer: Biochemistry, Molecular Biology and Genetics. Springer: New York, NY, 2013, pp 275-293.

8. Moodie SA, Willumsen BM, Weber MJ, Wolfman A. Complexes of Ras.GTP with Raf-1 and mitogen-activated protein kinase kinase. Science 1993; 260: 1658-1661.

9. Pylayeva-Gupta Y, Grabocka E, Bar-Sagi D. RAS oncogenes: weaving a tumorigenic web. Nat Rev Cancer 2011; 11: 761-774.

10. Mendoza MC, Er EE, Blenis J. The Ras-ERK and PI3K-mTOR pathways: cross-talk and compensation. Trends Biochem Sci 2011; 36: 320-328.

11. Castellano E, Downward J. RAS Interaction with PI3K: more than just another effector pathway. Genes Cancer 2011; 2: 261-274.

12. Calvisi DF, Ladu S, Conner EA, Seo D, Hsieh JT, Factor VM et al. Inactivation of Ras GTPase-activating proteins promotes unrestrained activity of wild-type Ras in human liver cancer. J Hepatol 2011; 54: 311-319.
13. von Bergh AR, Wijers PM, Groot AJ, van Zelderen-Bhola S, Falkenburg JH, Kluin PM et al. Identification of a novel RAS GTPase-activating protein (RASGAP) gene at $9 \mathrm{q} 34$ as an MLL fusion partner in a patient with de novo acute myeloid leukemia. Genes Chromosomes Cancer 2004; 39: 324-334.

14. Homayouni R, Magdaleno S, Keshvara L, Rice DS, Curran T. Interaction of Disabled-1 and the GTPase activating protein Dab2IP in mouse brain. Brain Res Mol Brain Res 2003; 115: 121-129.

15. Min J, Zaslavsky A, Fedele G, McLaughlin SK, Reczek EE, De Raedt T et al. An oncogenetumor suppressor cascade drives metastatic prostate cancer by coordinately activating Ras and nuclear factor-kappaB. Nat Med 2010; 16: 286-294.

16. Davis RJ. Signal transduction by the JNK group of MAP kinases. Cell 2000; 103: 239-252.

17. Zhang H, Zhang R, Luo Y, D'Alessio A, Pober JS, Min W. AIP1/DAB2IP, a novel member of the Ras-GAP family, transduces TRAF2-induced ASK1-JNK activation. J Biol Chem 2004; 279: 44955-44965.

18. Di Minin G, Bellazzo A, Dal Ferro M, Chiaruttini G, Nuzzo S, Bicciato S et al. Mutant p53 reprograms TNF signaling in cancer cells through interaction with the tumor suppressor DAB2IP. Mol Cell 2014; 56: 617-629.

19. Li X, Zhang R, Luo D, Park SJ, Wang Q, Kim Y et al. Tumor necrosis factor alpha-induced desumoylation and cytoplasmic translocation of homeodomain-interacting protein kinase 1 are critical for apoptosis signal-regulating kinase 1-JNK/p38 activation. J Biol Chem 2005; 280: 15061-15070.

20. Jager R, Bertrand MJ, Gorman AM, Vandenabeele P, Samali A. The unfolded protein response at the crossroads of cellular life and death during endoplasmic reticulum stress. Biol Cell 2012; 104: 259-270.

21. Clarke HJ, Chambers JE, Liniker E, Marciniak SJ. Endoplasmic reticulum stress in malignancy. Cancer Cell 2014; 25: 563-573.

22. Luo D, He Y, Zhang H, Yu L, Chen H, Xu Z et al. AIP1 is critical in transducing IRE1-mediated endoplasmic reticulum stress response. J Biol Chem 2008; 283: 11905-11912.

23. Guertin DA, Sabatini DM. Defining the role of mTOR in cancer. Cancer Cell 2007; 12: 9-22.

24. Fruman DA, Rommel C. PI3K and cancer: lessons, challenges and opportunities. Nat Rev Drug Discov 2014; 13: 140-156.

25. Xie D, Gore C, Zhou J, Pong RC, Zhang H, Yu L et al. DAB2IP coordinates both PI3K-Akt and ASK1 pathways for cell survival and apoptosis. Proc Natl Acad Sci USA 2009; 106: 19878-19883.

26. Clevers H. Wnt/beta-catenin signaling in development and disease. Cell 2006; 127: 469-480.

27. Price MA, Kalderon D. Proteolysis of the Hedgehog signaling effector Cubitus interruptus requires phosphorylation by Glycogen Synthase Kinase 3 and Casein Kinase 1. Cell 2002; 108: $823-835$.

28. Takenaka K, Kise Y, Miki H. GSK3beta positively regulates Hedgehog signaling through Sufu in mammalian cells. Biochem Biophys Res Commun 2007; 353: 501-508.

29. Robinson D, Van Allen EM, Wu YM, Schultz N, Lonigro RJ, Mosquera JM et al. Integrative clinical genomics of advanced prostate cancer. Cell 2015; 161: 1215-1228.

30. Wu K, Liu J, Tseng SF, Gore C, Ning Z, Sharifi N et al. The role of DAB2IP in androgen receptor activation during prostate cancer progression. Oncogene 2014; 33 : 1954-1963.

31. Du W, Ma XL, Zhao C, Liu T, Du YL, Kong WQ et al. Associations of single nucleotide polymorphisms in miR-146a, miR-196a, miR-149 and miR-499 with colorectal cancer susceptibility. Asian Pac J Cancer Prev 2014; 15: 1047-1055.

32. Yu H, Pardoll D, Jove R. STATs in cancer inflammation and immunity: a leading role for STAT3. Nat Rev Cancer 2009; 9: 798-809.

33. Min W, Pober JS. AIP1 in graft arteriosclerosis. Trends Cardiovasc Med 2011; 21: 229-233.

34. Yu L, Qin L, Zhang H, He Y, Chen H, Pober JS et al. AlP1 prevents graft arteriosclerosis by inhibiting interferon-gamma-dependent smooth muscle cell proliferation and intimal expansion. Circ Res 2011; 109: 418-427.

35. Wu K, Wang B, Chen $Y$, Zhou J, Huang J, Hui $K$ et al. DAB2IP regulates the chemoresistance to pirarubicin and tumor recurrence of non-muscle invasive bladder cancer through STAT3/Twist1/P-glycoprotein signaling. Cell Signal 2015; 27: 2515-2523.

36. Zhou J, Ning Z, Wang B, Yun EJ, Zhang T, Pong RC et al. DAB2IP loss confers the resistance of prostate cancer to androgen deprivation therapy through activating STAT3 and inhibiting apoptosis. Cell Death Dis 2015; 6: e1955.

37. Xie D, Gore C, Zhou J, Pong R-C, Zhang H, Yu L et al. DAB2IP coordinates both PI3K-Akt and ASK1 pathways for cell survival and apoptosis. Proc Natl Acad Sci USA 2009; 106: 19878-19883.

38. Min J, Liu L, Li X, Jiang J, Wang J, Zhang B et al. Absence of DAB2IP promotes cancer stem cell like signatures and indicates poor survival outcome in colorectal cancer. Sci Rep 2015; 5: 16578.

39. Zhang H, He Y, Dai S, Xu Z, Luo Y, Wan T et al. AIP1 functions as an endogenous inhibitor of VEGFR2-mediated signaling and inflammatory angiogenesis in mice. J Clin Invest 2008; 118: 3904-3916.

40. Zhang H, Zhang H, Lin Y, Li J, Pober JS, Min W. RIP1-mediated AIP1 phosphorylation at a 14-3-3-binding site is critical for tumor necrosis factor-induced ASK1-JNK/p38 activation. Biol Chem 2007; 282: 14788-14796.

41. Shen YJ, Kong ZL, Wan FN, Wang HK, Bian XJ, Gan HL et al. Downregulation of DAB2IP results in cell proliferation and invasion and contributes to unfavorable outcomes in bladder cancer. Cancer Sci 2014; 105: 704-712. 
42. Wang J, Zhu X, Hu J, He G, Li X, Wu P et al. The positive feedback between Snail and DAB2IP regulates EMT, invasion and metastasis in colorectal cancer. Oncotarget 2015; 6 : 27427-27439.

43. Marian CO, Yang L, Zou YS, Gore C, Pong RC, Shay JW et al. Evidence of epithelial to mesenchymal transition associated with increased tumorigenic potential in an immortalized normal prostate epithelial cell line. Prostate 2011; 71: 626-636.

44. Ji W, Li Y, He Y, Yin M, Zhou HJ, Boggon TJ et al. AlP1 expression in tumor niche suppresses tumor progression and metastasis. Cancer Res 2015; 75: 3492-3504.

45. Min J, Liu L, Li X, Jiang J, Wang J, Zhang B et al. Absence of DAB2IP promotes cancer stem cell like signatures and indicates poor survival outcome in colorectal cancer. Sci Rep 2015; 5: 16578.

46. Horiguchi K, Shirakihara T, Nakano A, Imamura T, Miyazono K, Saitoh M. Role of Ras signaling in the induction of snail by transforming growth factor-beta. J Biol Chem 2009; 284: 245-253.

47. Wang B, Huang J, Zhou J, Hui K, Xu S, Fan J et al. DAB2IP regulates EMT and metastasis of prostate cancer through targeting PROX 1 transcription and destabilizing $\mathrm{HIF} 1 \alpha$ protein. Cell Signal 2016; 28: 1623-1630.

48. Li S, Li Q, Yu W, Xiao Q. High glucose and/or high insulin affects HIF-1 signaling by regulating AIP1 in human umbilical vein endothelial cells. Diabetes Res Clin Pract 2015; 109: 48-56.

49. Zhou J, Luo J, Wu K, Yun EJ, Kapur P, Pong RC et al. Loss of DAB2IP in RCC cells enhances their growth and resistance to mTOR-targeted therapies. Oncogene 2016; 35: 4663-4674.

50. Medema JP. Cancer stem cells: the challenges ahead. Nat Cell Biol 2013; 15: 338-344.

51. Yun EJ, Baek ST, Xie D, Tseng SF, Dobin T, Hernandez E et al. DAB2IP regulates cancer stem cell phenotypes through modulating stem cell factor receptor and ZEB1. Oncogene 2015; 34: 2741-2752.

52. Colotta F, Allavena P, Sica A, Garlanda C, Mantovani A. Cancer-related inflammation, the seventh hallmark of cancer: links to genetic instability. Carcinogenesis 2009; 30: 1073-1081.

53. Grivennikov SI, Greten FR, Karin M. Immunity, inflammation, and cancer. Cell 2010; 140: 883-899.

54. Huang Q, Qin L, Dai S, Zhang H, Pasula S, Zhou H et al. AIP1 suppresses atherosclerosis by limiting hyperlipidemia-induced inflammation and vascular endothelial dysfunction. Arterioscler Thromb Vasc Biol 2013; 33: 795-804.

55. Wan T, Liu T, Zhang H, Tang S, Min W. AIP1 functions as Arf6-GAP to negatively regulate TLR4 signaling. J Biol Chem 2010; 285: 3750-3757.

56. Kong Z, Raghavan P, Xie D, Boike T, Burma S, Chen D et al. Epothilone B confers radiation dose enhancement in DAB2IP gene knock-down radioresistant prostate cancer cells. Int J Radiat Oncol Biol Phys 2010; 78: 1210-1218.

57. Yu L, Tumati V, Tseng S-F, Hsu F-M, Kim DN, Hong D et al. DAB2IP regulates autophagy in prostate cancer in response to combined treatment of radiation and a DNA-PKcs inhibitor. Neoplasia 2012; 14: 1203-1212.

58. Wu K, Xie D, Zou Y, Zhang T, Pong RC, Xiao G et al. The mechanism of DAB2IP in chemoresistance of prostate cancer cells. Clin Cancer Res 2013; 19: 4740-4749.

59. Yu L, Shang Z-F, Abdisalaam S, Lee K-J, Gupta A, Hsieh J-T et al. Tumor suppressor protein DAB2IP participates in chromosomal stability maintenance through activating spindle assembly checkpoint and stabilizing kinetochore-microtubule attachments. Nucleic Acids Res 2016; 44: 8842-8854.

60. Chen H, Toyooka S, Gazdar AF, Hsieh JT. Epigenetic regulation of a novel tumor suppressor gene (hDAB2IP) in prostate cancer cell lines. J Biol Chem 2003; 278: 3121-3130.

61. Dote H, Toyooka S, Tsukuda K, Yano M, Ouchida M, Doihara H et al. Aberrant promoter methylation in human DAB2 interactive protein (hDAB2IP) gene in breast cancer. Clin Cancer Res 2004; 10: 2082-2089.

62. Dote H, Toyooka S, Tsukuda K, Yano M, Ota T, Murakami M et al. Aberrant promoter methylation in human DAB2 interactive protein (hDAB2IP) gene in gastrointestinal tumour. $\mathrm{Br}$ $J$ Cancer 2005; 92: 1117-1125.

63. Yano M, Toyooka S, Tsukuda K, Dote H, Ouchida M, Hanabata T et al. Aberrant promoter methylation of human DAB2 interactive protein (hDAB2IP) gene in lung cancers. Int $J$ Cancer 2005; 113: 59-66.

64. Qiu GH, Xie H, Wheelhouse N, Harrison D, Chen GG, Salto-Tellez M et al. Differential expression of hDAB2IPA and hDAB2IPB in normal tissues and promoter methylation of hDAB2IPA in hepatocellular carcinoma. J Hepatol 2007; 46: 655-663.

65. Chen H, Tu SW, Hsieh JT. Down-regulation of human DAB2IP gene expression mediated by polycomb Ezh2 complex and histone deacetylase in prostate cancer. J Biol Chem 2005; 280: 22437-22444.

66. Chen Y, Dong X, Yu D, Wang X. Serum miR-96 is a promising biomarker for hepatocellular carcinoma in patients with chronic hepatitis B virus infection. Int J Clin Exp Med 2015; 8: 18462-18468.

67. Kim KH, Roberts CWM. Targeting EZH2 in cancer. Nat Med 2016; 22: 128-134.

68. Smits M, van Rijn S, Hulleman E, Biesmans D, van Vuurden DG, Kool M et al. EZH2regulated DAB2IP is a medulloblastoma tumor suppressor and a positive marker for survival. Clin Cancer Res 2012; 18: 4048-4058.

69. Barik S. An intronic microRNA silences genes that are functionally antagonistic to its host gene. Nucleic Acids Res 2008; 36: 5232-5241.

70. Xu Y, He J, Wang Y, Zhu X, Pan Q, Xie $Q$ et al. miR-889 promotes proliferation of esophageal squamous cell carcinomas through DAB2IP. FEBS Lett 2015; 589: 1127-1135

71. Liao H, Xiao Y, Hu Y, Xiao Y, Yin Z, Liu L. MicroRNA-32 induces radioresistance by targeting DAB2IP and regulating autophagy in prostate cancer cells. Oncol Lett 2015; 10: 2055-2062.

72. Huang J, Wang B, Hui K, Zeng J, Fan J, Wang $X$ et al. miR-92b targets DAB2IP to promote EMT in bladder cancer migration and invasion. Oncol Rep 2016; 36: 1693-1701.

73. Adams BD, Kasinski AL, Slack FJ. Aberrant regulation and function of microRNAs in cancer. Curr Biol 2014; 24: R762-R776.

74. Dai X, North BJ, Inuzuka H. Negative regulation of DAB2IP by Akt and SCFFbw7 pathways. Oncotarget 2014; 5: 3307-3315.

75. Tsai YS, Lai CL, Lai CH, Chang KH, Wu K, Tseng SF et al. The role of homeostatic regulation between tumor suppressor DAB2IP and oncogenic Skp2 in prostate cancer growth. Oncotarget 2014; 5: 6425-6436.

76. Li X, Dai X, Wan L, Inuzuka H, Sun L, North BJ. Smurf1 regulation of DAB2IP controls cell proliferation and migration. Oncotarget 2016; 7: 26057-26069.

77. Zhang X, Li N, Li X, Zhao W, Qiao Y, Liang L et al. Low expression of DAB2IP contributes to malignant development and poor prognosis in hepatocellular carcinoma. $J$ Gastroenterol Hepatol 2012; 27: 1117-1125.

78. Jacobs C, Tumati V, Kapur P, Yan J, Xie XJ, Hannan R et al. Pretreatment biopsy analysis of DAB2IP identifies subpopulation of high-risk prostate cancer patients with worse survival following radiation therapy. Cancer Med 2015; 4: 1844-1852.

79. Musacchio A, Gibson T, Rice P, Thompson J, Saraste M. The PH domain: a common piece in the structural patchwork of signalling proteins. Trends Biochem Sci 1993; 18 : 343-348.

80. Nalefski EA, Falke JJ. The C2 domain calcium-binding motif: structural and functional diversity. Protein Sci 1996; 5: 2375-2390.

81. Boguski MS, McCormick F. Proteins regulating Ras and its relatives. Nature 1993; 366 : 643-654.

82. Feller SM, Ren R, Hanafusa H, Baltimore D. SH2 and SH3 domains as molecular adhesives: the interactions of Crk and Abl. Trends Biochem Sci 1994; 19: 453-458.

83. Hui S, Xing X, Bader GD. Predicting PDZ domain mediated protein interactions from structure. BMC Bioinformatics 2013; 14: 27.

84. Perkins ND. Integrating cell-signalling pathways with NF-kappaB and IKK function. Nat Rev Mol Cell Biol 2007; 8: 49-62.

85. Wajant H, Pfizenmaier K, Scheurich P. Tumor necrosis factor signaling. Cell Death Differ 2003; 10: 45-65.

86. Kalliolias GD, Ivashkiv LB. TNF biology, pathogenic mechanisms and emerging therapeutic strategies. Nat Rev Rheumatol 2016; 12: 49-62.

87. Min W, Lin Y, Tang S, Yu L, Zhang H, Wan T et al. AlP1 recruits phosphatase PP2A to ASK1 in tumor necrosis factor-induced ASK1-JNK activation. Circ Res 2008; 102: 840-848.

88. Zhou HJ, Chen $X$, Huang $Q$, Liu R, Zhang $H$, Wang $Y$ et al. AlP1 mediates vascular endothelial cell growth factor receptor-3-dependent angiogenic and lymphangiogenic responses. Arterioscler Thromb Vasc Biol 2014; 34: 603-615.

89. Ji W, Li Y, Wan T, Wang J, Zhang H, Chen $\mathrm{H}$ et al. Both internalization and AIP1 association are required for tumor necrosis factor receptor 2-mediated JNK signaling. Arterioscler Thromb Vasc Biol 2012; 32: 2271-2279. 